\title{
Remote Sensing in Urban Forestry: Recent Applications and Future Directions
}

\author{
Xun $\mathrm{Li}^{1}{ }^{1}$, Wendy Y. Chen $^{1}$, Giovanni Sanesi ${ }^{2}$ and Raffaele Lafortezza ${ }^{1,2, *(D)}$ \\ 1 Department of Geography, The University of Hong Kong, Pokfulam Road, Hong Kong SAR, China; \\ u3003456@connect.hku.hk (X.L.); wychen@hku.hk (W.Y.C.) \\ 2 Department of Agricultural and Environmental Sciences, University of Bari "Aldo Moro", \\ Via Amendola 165/A, 70126 Bari, Italy; giovanni.sanesi@uniba.it \\ * Correspondence: raffaele.lafortezza@uniba.it or raffa@hku.hk
}

Received: 22 March 2019; Accepted: 8 May 2019; Published: 14 May 2019

\begin{abstract}
Increasing recognition of the importance of urban forest ecosystem services calls for the sustainable management of urban forests, which requires timely and accurate information on the status, trends and interactions between socioeconomic and ecological processes pertaining to urban forests. In this regard, remote sensing, especially with its recent advances in sensors and data processing methods, has emerged as a premier and useful observational and analytical tool. This study summarises recent remote sensing applications in urban forestry from the perspective of three distinctive themes: multi-source, multi-temporal and multi-scale inputs. It reviews how different sources of remotely sensed data offer a fast, replicable and scalable way to quantify urban forest dynamics at varying spatiotemporal scales on a case-by-case basis. Combined optical imagery and LiDAR data results as the most promising among multi-source inputs; in addition, future efforts should focus on enhancing data processing efficiency. For long-term multi-temporal inputs, in the event satellite imagery is the only available data source, future work should improve haze-/cloud-removal techniques for enhancing image quality. Current attention given to multi-scale inputs remains limited; hence, future studies should be more aware of scale effects and cautiously draw conclusions.
\end{abstract}

Keywords: remote sensing; urban forest; Ecosystem services; LiDAR; multi-source data

\section{Introduction}

The world is experiencing accelerated urbanisation and growth of cities [1,2], which have dramatically changed the urban landscape [3-5]. Though frequently escaping our notice, a mosaic of fragmented habitats exists, ranging from remnant natural, modified natural, semi-natural, emulated natural or entirely human-created, where diverse trees and other vegetation thrive [6,7]. Collectively, all woods and trees within a city boundary are defined as an urban forest, including individual trees, forest stands, and their associated biotic and abiotic components [8-11]. Complex forest patches are a critical component of urban ecosystems. They provide a full spectrum of ecosystem services, referring to the benefits that human populations obtain directly or indirectly $[7,12,13]$ from natural ecosystems [14,15], which serve as the basis of economic development and social wellbeing [16-18]. Some well-recognised and well-studied examples of urban forest ecosystem services include alleviating summer heat through evaporation and shading $[19,20]$, reducing stormwater runoff by intercepting and absorbing water and improving infiltration [21,22], enhancing air quality by removing gaseous pollutants and particulate matter [23], reducing greenhouse gas emissions by storing and sequestering a considerable amount of carbon [24-27]; addressing food security by supplying food, medicine and materials [28], pollination [29-31], outdoor recreation opportunities [1,32], as well as serving as important places for aesthetics and spirituality $[33,34]$. 
In line with the increasing recognition of the importance of urban forest ecosystem services, there are calls around the world for the adequate installation and sustainable management of urban forests to maintain environmental health, improve the resilience of urban ecosystems, and enhance the quality of urban life $[2,35,36]$. Given their great socio-ecological complexity and dynamics, urban forests are by no means stationary $[4,11,37]$. The successful management of urban forests for the steady and sustainable provision of a full spectrum of ecosystem services requires timely and accurate information on the status, trends, and information about interactions between socioeconomic and ecological processes pertaining to urban forests occurring at multiple temporal and spatial scales $[2,35,38,39]$. Traditionally, such information has been obtained by random field sampling and visual interpretation of aerial photos, which are expensive, generally labour-intensive and time-consuming, and usually cannot provide complete coverage of relatively large areas of interest [40-42]. These traditional approaches have curtailed the accurate, consistent, replicable, and spatially explicit measurement of spatiotemporal changes of urban forests and the associated evaluation of ecosystem service provision $[43,44]$. Consequently, research faces challenges due to non-uniform and multifunctional approaches, different methodologies, and a lack of relevant information [27].

Fortunately, remote sensing, especially the latest advanced techniques and sensors (e.g., light detection and ranging LiDAR technology, hyperspectral imagery, high spatial resolution satellite imagery), has emerged as a premier and useful observational and analytical tool that offers a fast, replicable, objective, efficient, scalable, and cost-effective way to assess and quantify urban forest dynamics at varying spatiotemporal scales $[5,43,45]$. For instance, the structural (3D arrangement of vegetation, such as tree height, volume and size of foliage and stems), compositional (species richness and diversity), and functional (ecological processes) characteristics of an individual tree, urban forest patch, or all urban forests in large areas can be detected, measured, mapped, inventoried, classified, monitored, modelled, and evaluated using remote sensing techniques [35,46]. Over the past decade, the application of remote sensing in urban forestry, particularly the quantification of biophysical dimensions of urban forests and associated ecosystem services, has increased $[43,44,47,48]$, although its use is still comparatively modest for studying spatially and spectrally complex urban forest ecosystems [35,49].

In this study, we aim to summarise recent applications of remote sensing in urban forestry from the perspective of three distinctive themes, i.e., multi-source, multi-temporal, and multi-scale (referring to studies conducted at different spatial scales) inputs. The state-of-art is evaluated on the basis of empirical studies from the past decade. In particular, we exemplify how highly detailed and replicable information on urban forests can be successfully derived from remotely sensed imagery over areas at various spatiotemporal scales, which significantly surpasses the capacities of traditional inventory or image analysis techniques [50]. Lastly, we discuss the potential of remote sensing to improve the reliability and accuracy of mapping urban forest structural, functional and configurational properties and dynamics, as well as of estimating a suite of ecosystem services.

\section{Remote Sensing Applications in Urban Forests}

To summarise recent applications of remote sensing in the field of urban forestry, we focused our search on research articles published in peer-reviewed journals, in English, within the time span between January 2013 and March 2019. Multiple databases, including ISI Web of Science, Elsevier's Scopus, Google Scholar and ScienceDirect, were browsed using the terms "remote sensing OR LiDAR" AND "urban forest OR tree OR plant OR vegetation OR greenspace". More than 200 studies were found to satisfy the aforementioned conditions. These studies were further filtered based on the following criteria:

(1) The research must focus exclusively on urban forests or greenspaces. Studies involving natural forests are excluded. 
(2) The research must use remotely sensed data obtained from airborne/spaceborne imagery or LiDAR. Studies involving data based on other techniques, such as pure photogrammetry or terrestrial-based methods, are excluded.

(3) The research must involve at least one of the three themes: multi-source, multi-temporal, and multi-scale inputs. Studies unrelated to any of these themes are excluded.

The final number of studies found totalled 63; these were classified in terms of 10 different applications and three distinctive themes (Table 1). A detailed description of each study is reported in Supplementary Materials. The articles cover remote sensing applications in diverse areas, including measurement of urban forest attributes (e.g., biomass, species composition, canopy cover and spatial configuration) and quantification of ecosystem services (e.g., carbon storage, water retention, air quality improvement, and urban heat island mitigation). In the following sections, the articles are reviewed and discussed in terms of the themes multi-source, multi-temporal and multi-scale input; their strengths and limitations are summarised in Table 2.

\subsection{Theme 1: Multi-Source Input}

A shift from the use of single-source remote sensing data (11 of 63) to multi-source remote sensing data (52 of 63) in urban forest studies has been observed thanks to the emergence of diverse airborne and spaceborne platforms and the rapid development of remote sensing techniques. Examples of these are the emerging very high spatial resolution (VHSR) and high spatial resolution (HSR) sensors, hyperspectral sensors and high point density LiDAR technology. Table 3 lists the remote sensing products/platforms used for urban forest studies. Two examples, as shown in Figure 1, are satellite imagery (WorldView-2 NDVI) and LiDAR point-cloud data (canopy height model) applied to urban forests at both macro- and micro-scale. Quantum leaps in computing power have enabled researchers to fuse, process and model data from various sources at an unprecedented level of spatial and temporal resolution.

\subsubsection{Multiple Sources of Satellite Imagery}

The combination of multiple sources of satellite imagery offers new potential in ecological research. In fact, the majority of studies addressing the link between urban greenspace and urban heat island rely on satellite images from multiple sources (Table 1). While HSR optical images, such as SPOT and IKONOS, are able to classify vegetation coverage and other land uses at a fine level, these optical sensors do not provide thermal infrared information. Indeed, land surface temperature has been derived from other images with thermal bands, such as Landsat and Terra/MODIS sensors. As satellite images from various sources complement one another, scientists overcome the technical challenges associated with a limited spatial, spectral, temporal, and radiometric resolution by creatively combining various satellite sources. Moreover, the increasing availability of free data is an incentive to utilise multiple sources of satellite imagery. Although there are certain advantages of fee-based imagery (e.g., very high spatial, temporal and spectral resolution) that cannot be replaced by open-access data, these data sharing platforms allow researchers to download a variety of satellite images from high-quality sources. Two such examples are the online platform operated by the United States Geological Survey (USGS) (https://earthexplorer.usgs.gov/) and the Sentinel online platform operated by the European Space Agency (ESA) (https://sentinel.esa.int/web/sentinel/home). Other ready-made global/regional land cover and land use products, such as CORINE and Geo-Wiki, can be directly used for analysis. Nonetheless, research should be the foremost consideration when it comes to the selection of satellite imagery.

For example, Ren et al. [51] examined the relationship between urban park features and park cool island intensity in Changchun, China using multi-source satellite imagery. The urban land surface temperature was derived from Landsat-5 Thematic Mapper (TM) thermal band using the mono-window method proposed by Qin et al. [52]. SPOT images were used to extract urban park spatial features like size and shape. 
Kong et al. [53] used two sources of satellite imagery, IKONOS and Landsat-5 (TM) images, to explore the impacts of spatial greenspace pattern on the urban heat island effect in a large metropolitan area in eastern China. The HSR IKONOS images were used to classify land use into six types. Band 6 of Landsat-5 (TM) imagery was able to provide thermal infrared data that could be used to estimate land surface temperature. Aligned with the spatial resolution of the land use map, the land surface temperature map was resampled at $5 \mathrm{~m} \times 5 \mathrm{~m}$. The land use map was employed to calculate landscape indices, which were used to estimate the spatial pattern of greenspace and to analyse its relationship with land surface temperature. It was found that the greenspace pattern significantly influenced the urban cooling effect. Greater urban cooling effects were observed in areas with a high percentage of greenspace cover and level of greenspace fragmentation.

In addition to quantifying the urban cooling effect of urban greenspaces, multi-source remote sensing has also been recently applied to address other research objectives. Modugno et al. [54] mapped forest fires in the wildland-urban interface areas across Europe based on the harmonised land use and land cover change map CORINE 2006. The CORINE land cover product derived from multi-source satellite imagery is a commonly used dataset for European continental scale studies $[55,56]$ and has been updated every six years since 2000. The CORINE 2006 dataset selected in this study is based on SPOT-4/-5 and IRS P6 satellite imagery. The forest fire information was extracted from the Burned Surfaces Product, which was derived from the European Forest Fire Information System using MODIS images. It revealed all forest fires burning 40 ha of surface area. Instantly accessible harmonised datasets (e.g., CORINE land cover product and burned surfaces product) based on multi-source satellite imagery have enabled researchers to evaluate attributes of urban forests with high efficiency.

In general, the application of the multi-source approach could be limited by two technical barriers. First, weather conditions (e.g., haze and cloud coverage) and different image dates; both pose major challenges and there is no guarantee that all images obtained within a certain time period are of high quality for classification purposes. For example, in their 20-year temporal analysis, Di Leo et al. [57] discarded poor-quality images affected by cloudiness or haze. The feasibility of using multiple sources of satellite imagery should be a primary consideration, especially for time-sensitive research. Second, satellite images are rarely available at both HSR and spectral resolution. Hyperion EO- 1 imagery is one of the few hyperspectral satellite images with 242 bands, yet it only has a spatial resolution of $30 \mathrm{~m}$. Till now, few tree-level studies (e.g., identifying individual tree species and tree crowns) have relied solely on multiple source applications of satellite images.

\subsubsection{Satellite Imagery and Airborne LiDAR}

Due to the strengths in providing spectral details and 3D point clouds, VHSR/HSR satellite imagery and airborne LiDAR data were suited for the estimation of urban forest structure, attributes and carbon storage. The integration of optical satellite imagery and LiDAR data allows us to identify the urban forest structure more accurately in a complex urban environment. HSR multispectral imagery is able to produce precise vegetation coverage, upon which LiDAR point-cloud data are based and can be further used to estimate tree-level structure.

For example, Raciti et al. [58] mapped carbon storage of urban trees in Boston City using LiDAR data coupled with VHSR satellite images. QuickBird imagery was first employed to derive the Normalised Difference Vegetation Index (NDVI) values for extracting the vegetation cover. Subsequently, 3D airborne LiDAR point-cloud data were used to delineate individual tree crowns within the vegetation coverage. LiDAR-based tree height data were further used to estimate biomass and carbon storage. The results showed that previous work using single-source remotely sensed data tended to overestimate carbon storage in Boston. The QuickBird-LiDAR approach presented in this study displayed high accuracy in estimating stereo features of urban trees, like volume and biomass.

Similarly, Schreyer et al. [59] developed a more specific method to combine LiDAR data and VHSR satellite images to evaluate the carbon storage of urban trees in Berlin, Germany. Airborne LiDAR was first employed to generate a digital surface model (DSM) and a digital terrain model (DTM). 
After a vegetation mask was created based on QuickBird imagery, the DSM and DTM were used to derive a canopy height model (CHM). Using a two-step approach [60,61], dendrometric parameters including tree location, number, height, crown width and diameter at breast height were generated from the CHM. These parameters were then used to calculate carbon storage and distribution among urban trees.

Parmehr et al. [62] used a novel data fusion strategy to identify urban tree canopy cover with WorldView-2 imagery and airborne LiDAR data. The investigators adopted an automatic co-registration method, which was proposed by Parmehr et al. [63]. The co-registration of satellite imagery to LiDAR data is a process known as point-cloud colourisation. It attaches spectral information to the LiDAR point cloud so that each colourised LiDAR point has additional RGB and NDVI values. The NDVI values can improve the accuracy of identifying LiDAR tree points during the segmentation of trees from other urban objects. Data fusion of LiDAR point-cloud data and spectral imagery has great potential in increasing the accuracy of estimating tree structure in complex urban environments with diversified tree canopy shapes and terrains.

While most recent studies agree that the combination of satellite imagery and LiDAR data can lead to higher estimation accuracy, a publication by Singh et al. [64] challenges this consensus. The authors found that with the help of a random forest classification method, LiDAR-derived topography metrics could detect understory plant invasion in urban forests with the highest accuracy, exceeding IKONOS data by $17.5 \%$ and combined LiDAR and IKONOS data by $5.3 \%$. In this case, they inferred that the temporal lag that took place between LiDAR and IKONOS data collection might have affected the accuracy of identifying the fast-growing invasive species, Ligustrum sinense. The off-nadir effect of tall trees [65] would also hamper HSR satellite imagery in detecting understory features in a heterogeneous urban environment.

Although some researchers argue that airborne LiDAR alone is capable of producing an accurate tree-level analysis, the abundance of spectral details provided by satellite imagery should be corroborated; managed properly it can significantly enhance estimation accuracy as opposed to using LiDAR data alone. Point-cloud colourisation is a promising technique for remote sensing data fusion. By combining every LiDAR point with spectral information extracted from satellite imagery, the colourised 3D point clouds with NDVI can be employed not only for segmenting individual trees but also for distinguishing trees from their surrounding urban environments. Nonetheless, it should be noted that the estimation accuracy of combining satellite imagery and LiDAR data would be reduced if the fetch interval between the two data sources is relatively long, or if the research objects are understory urban forests.

\subsubsection{Satellite Imagery and Aerial Imagery}

In practice, the combination of satellite imagery and aerial imagery has seldom been adopted, given that aerial imagery can replace satellite imagery in terms of optical capability. Only when extra data, such as infrared and thermal infrared data, are needed would such a combination become necessary. The majority of recent publications utilising both satellite and aerial imagery (three of five) have studied the mitigation effect of urban forests on the urban heat island. For example, Sung [66] estimated how the woodlands' tree protection policy adopted by The Woodlands Township, Texas, USA, affected the urban heat island at the neighbourhood level. The author compared the land surface temperature of two neighbourhoods in the woodlands and five control neighbourhoods in other urban areas. The land surface temperature was obtained from the thermal bands of Landsat-5 (TM) imagery. Unlike most urban cooling studies that used HSR satellite imagery to extract land use information, this study exploited the US National Agricultural Imagery Program's (NAIP) aerial imagery to classify land cover at a fine scale. An object-based method was coupled with a support vector machine (SVM) classifier to identify trees. When dealing with high-resolution imagery, object-based methods have been reported to be superior to pixel-based methods for their ability to reduce noise and increase accuracy $[67,68]$. Aerial imagery is superior to satellite imagery in terms of concurrent high spatial 
and spectral resolution. However, prohibitive flight costs limit its use to small/moderate areas. In the US, NAIP has been offering aerial imagery with continental coverage during the agricultural growing seasons to the public since 2003. NAIP imagery with four spectral bands is acquired at a 1-m ground sample distance with horizontal accuracy that matches within $6 \mathrm{~m}$ of ground control points, which can be used during image inspection and processing. A number of recent urban forest studies have benefitted from free NAIP images.

\subsubsection{Airborne LiDAR and Aerial Imagery}

The integration of airborne LiDAR and aerial imagery has recently gained popularity in tree-level urban forest inventories. It has great potential not only for enhancing estimation accuracy but also for increasing the number of identifiable tree species. However, the limited coverage and expensive flight costs of LiDAR hamper its use at a large scale. Alonzo et al. [69], for example, found that by using fused HSR hyperspectral AVIRIS imagery with high point density LiDAR data, 29 common urban tree species at crown level could be clearly identified. This was a substantial improvement compared to 15 species identified using AVIRIS imagery alone, as reported in an earlier study [70]. Even though the addition of LiDAR data could increase the overall accuracy by only $4.2 \%$, it was able to enhance the classification accuracy of certain species, especially small crowned species, by more than 10\%. Later, Alonzo et al. [43] found that fused airborne LiDAR and aerial imagery could outperform field-plot data when measuring the uneven distribution of canopies across the city. Compared to field-plot data, the consistency of airborne fused data is very suitable for measuring hard-to-access urban areas or for large-scale measurements that require replication. These studies confirm the merits of using hyperspectral imagery and LiDAR data fusion in mapping crown-level tree species in a highly heterogeneous urban environment.

Zhang et al. [71] designed a framework to integrate airborne LiDAR data and aerial images for a tree-level urban forest inventory. Above-ground points were separated from ground points in the LiDAR data. The authors innovatively used NDVI values derived from hyperspectral images to separate vegetation points from non-vegetation points. The ground points and vegetation points were used to isolate individual trees with a treetop detection algorithm and a tree boundary extraction algorithm. Lastly, tree species could be delineated in the hyperspectral images. Although this method was able to increase the accuracy of tree-level identification, it was computationally demanding and not scalable to larger spatial scales. Future work should focus on algorithm optimisation and computing hardware upgrade to improve data processing efficiency.

The high point density of airborne LiDAR coupled with the high spectral resolution of aerial imagery is an exciting approach for fine estimation. High-density 3D point clouds and high spatial and spectral resolutions together can ensure high estimation accuracy. More importantly, unlike satellite imagery, the quality of the fused data is not compromised by synoptic conditions, because the data are obtained via active sensors. However, expensive flight costs and time-consuming data processing limit its tractability for large-scale applications.

\subsection{Theme 2: Multi-Temporal Input}

Cross-sectional modelling of urban forest attributes and their ecosystem services might be biased by unobserved factors. A useful strategy to mitigate this bias is to replicate observations of the same units over time, thus time-invariant and location-specific unobserved factors can be controlled [72]. In particular, multi-temporal remotely sensed data carry great potential for capturing local details and have greater potential to improve estimation accuracy based on locally detailed and spatially explicit data input. For example, using multi-temporal image data can increase the success rate of mapping urban tree species composition as phenological information is retrieved [41,48]; this could be of vital importance for urban forests due to their compositional and configurational complexity and heterogeneity. Due to such potential, empirical studies have made use of short or long series multi-temporal remote sensing datasets to estimate changes in urban forest compositional 
and configurational attributes (e.g., dominant species, forest age, canopy density); hence, a reliable relationship between urban forests and the ecosystem services they provide is established.

\subsubsection{Short Series Data Input}

Some studies have utilised short series (usually only two) datasets to estimate changes in urban heat island effects and the urban forest structure during a given time span, especially before and after a certain event. Rogan et al. [73] integrated satellite and aerial images to examine the change in urban heat island effect induced by eradicating the invasive Asian Longhorned Beetle, which caused the elimination of 30,000 trees since 2008 in central urban areas in Massachusetts, USA. Landsat-5 (TM) thermal images acquired in the summertime in 2008 and 2010 were used to obtain land surface temperature. NAIP images also acquired in both years during leaf-on conditions were used to extract tree canopy cover. The authors found that the large amounts of tree loss and increased impervious surface between 2008 and 2010 were significant in determining the increased land surface temperature.

Similarly, Landsat-5 and -8 images from 2004 and 2014 were examined to detect changes in urban forest structure in Jinjiang city, southern China [74]. Combined together with ground observations and spatial statistical modelling, the mechanisms that influence the surface temperatures of urban forest canopies were successfully explored.

Qian et al. [75,76] utilised HSR and multispectral satellite images to explore the changes in urban greenspace configuration induced by the 2008 Olympic Games in Beijing, China. Taking advantage of both the HSR and multispectral features of SPOT and ALOS images taken in 2005 and 2008, fine-scale greenspace coverage and landscape indices were derived for spatial analysis. The authors found that holding the Olympic Games in Beijing not only incentivised the local government to increase greenspace coverage but also changed the spatial pattern of greenspaces across the city.

\subsubsection{Long Series Data Input}

The majority of recent studies uses multi-temporal data to study changes in urban forests and the induced socioeconomic and environmental effects based on long series data input (16 of 26). The ability of multi-temporal remote sensing to monitor long-term changes in urban vegetation cover, urban forest structure, and urban heat island is profound. Its potential also lies in monitoring changes at various scales, from a small urban park to a metropolitan city and even to an entire region or nation. Landsat imagery has been largely used by long-term studies owing to its long and continuous time-series. MODIS imagery is also popular in urban heat island studies because it has a superior temporal resolution than Landsat. The advantages of using multi-temporal satellite images for a long-term, multi-temporal study are apparent: low cost, instant access, and short revisit period.

Yang et al. [77] estimated the changes in urban greenspace coverage in 30 major Chinese cities at regional level between 1990 and 2010. Landsat-5 (TM) and Landsat-7 Enhanced Thematic Mapper Plus (ETM+) images acquired in 1990, 2000 and 2010 were used to classify land cover into five types with the SVM method. They found highly divergent trends of urban greenspace changes across different cities, which could be explained by varied developmental patterns and government policies.

Adam and Smith [78] explored the relationship between vegetation cover and urban heat island effect across the greater Sydney metropolitan region, in Australia. All available MODIS thermal band scenes (102 in total) with less than 5\% cloud cover in the summertime between 2000 and 2011 were used as the land surface temperature index. The vegetation cover indices (e.g., foliage projective cover, fractional cover of photosynthetically active vegetation) were extracted based on Landsat imagery and ancillary data within the same time-series. All indices were resampled to $1 \mathrm{~km}^{2}$ to match MODIS spatial resolution. Unlike most previous studies that employed single-phase remotely sensed data and a single mode of measuring vegetation cover, the multi-temporal satellite imagery employed in this study was capable of accounting for temporal variability and estimating the regional effects of varying density and structure of vegetation cover. 
Bae and Ryu [79] examined the spatial and temporal variations of soil organic carbon stock in a constructed urban park in Seoul, Korea, and explored how soil organic carbon stock was shaped by land use and land cover changes. In their study, the NDVI values were derived from MODIS data. Landsat-7 and -8 time-series images acquired between 2003 and 2013 were collected to measure the temporal changes in NDVI values and land use pattern. Changes in the soil organic carbon concentration of topsoil were quantified based on land use types. The results indicated that land use history of the urban park played an important role in the temporal variations of the soil organic carbon concentrations.

Di Leo et al. [57] explored the role of urban green infrastructure in mitigating the urban heat island effect over 20 years in an urban area in sub-Saharan Africa. A total of 16 processed satellite images acquired from Landsat-5 (TM), Landsat-7 (ETM+) and Landsat-8 Operational Land Imager and Thermal Infrared Sensor (OLI/TIRS) between 1991 and 2013 were used to extract data on greenspace cover and land surface temperature. Data alignment was required for multi-temporal images from different Landsat sensors. On the one hand, the spatial resolutions of the thermal bands of the three Landsat sensors were different: $120 \mathrm{~m}$ for Landsat-5, $60 \mathrm{~m}$ for Landsat-7, and $100 \mathrm{~m}$ for Landsat- 8 . On the other hand, the thermal resolutions were also divergent: Landsat- 5 and Landsat- 7 had only one thermal band (Band 6), while Landsat- 8 had two thermal bands (Band 10 and Band 11). This study demonstrates the advantages of multi-temporal satellite images in supporting spatiotemporal studies of urban forests and the urban heat island. However, the insufficient number of high-quality periodic satellite images for a 20-year analysis constitutes a critical limitation in this study.

Overall, for long-term high-frequency monitoring it is difficult to ensure that all images are cloud-free, despite the tools available on Earth Explorer and Google Earth Engine that allow researchers to select the most cloud-free scenes from the library. Sensor anomalies, as found with Landsat (https://www.usgs.gov/land-resources/nli/landsat/landsat-known-issues), may also impact long-term data collection. Accordingly, multi-source data are sometimes required to compensate the need for high-quality images.

\subsection{Theme 3: Multi-Scale Input}

The relationship between urban forests and ecosystem services has been shown to vary across space at different scales [72,80]. Indeed, one of the key advantages of remote sensing is its scalability. Correspondingly, a more recent theme in remote sensing application in urban forests is the emergence of multi-scale studies, expanding from micro-scale (e.g., individual tree and park patch) to meso-scale (e.g., city) and macro-scale (e.g., regional analysis), although relatively limited attention has been given to this aspect (eight of 63 studies). Multi-scale studies are complex to carry out and require a thorough knowledge of different sensors and algorithms for fusing multiple images.

\subsubsection{Local- and City-Scales}

Duncan et al. [72] assessed how urban vegetation configuration (grass, shrub and tree) influences urban temperatures in Perth, Australia. The authors used multi-temporal, very fine spatial $(20-\mathrm{cm})$ and vertical (1-mm) resolution aerial imagery (provided by Urban MonitorTM from the Commonwealth Scientific and Industrial Research Organisation), as well as MODIS land surface temperature data (from the Terra satellite and Aqua satellite) for the 2003 to 2016 time period. In the study, local detailed and multiple time-period inputs were incorporated into urban climate modelling at local- and city-scales.

The benefit of urban forests in mitigating runoff in highly urbanised central Beijing (the capital city of China) was measured in another study using IKONOS images with four spectral bands captured in July 2012 [81]. In this study, spatial data pertaining to land cover types (including the tree canopy of an urban forest) were extracted and used as input of a hydrologic model to simulate various runoff scenarios from small sites to the entire study area.

More generally, a spatially explicit multi-scale indicator was developed to integrate social data (residents' perception of multiple ecosystem services provided by urban forests) with remote sensing 
data (from high-resolution satellite images and LiDAR) to understand how the provision of ecosystem services is distributed in a city and predict how people perceive their provision across the entire urban landscape [5]. In particular, this modelling process and the indicator proposed can be easily scaled up to large regional scale and beyond.

\subsubsection{City- and Regional Scales}

Due to the considerable spatial heterogeneity of urban forests across large areas, regional analysis of urban forests and associated ecosystem services using remote sensing techniques is still rarely conducted. Nevertheless, urban tree canopy cover in Los Angeles and Sacramento, California was mapped using QuickBird satellite and aerial imagery [82]. Combined with field survey data (e.g., age and species composition of urban trees), carbon storage and sequestration density were quantified across the study region.

At the national level, Landsat-5 (TM) and Landsat-7 (ETM+) SLC-on images with a processing level at Level 1T of 30 Chinese cities in 1990, 2000, and 2010 (obtained from the Earth Resources Observation and Science Center, USGS) were used to investigate changes in urban green spaces [77]. Combined with socioeconomic and natural data, the potential driving forces behind the identified changes were then explored.

\section{Challenges and Future Directions}

The volume of remote sensing images continues to grow at an enormous rate due to rapid advances in sensor technology and the launch of new satellite constellations. Consequently, an increasing amount of images from various sensors have become available, including multi-resolution and multi-temporal as well as multi-spectral band images. Despite this upsurge in trends, challenges have emerged in the field of urban forestry concerning the use of remote sensing techniques and the realisation of their full potential. First, although many remote sensing data and products are available (Table 3), there are technical issues with regard to data fusion and synergy (such as fusing optical, hyperspectral imagery, synthetic aperture radar remote sensing data that operate at disparate resolutions and use diverse acquisition approaches) as well as data matching to meet urban foresters' practical needs [35]. Second, a direct link is still lacking between ecological and geographical features, which can be extracted from remote sensing, and the adequate monitoring and modelling of ecosystem services provision, which usually requires diverse data inputs and sophisticated data processing [27]. Third, although several urban forest management software programmes (e.g., i-Tree developed by the USDA Forest Service) have standardised remote sensing data inputs, they are far from being developed as internationally transferable tools due to insufficient field calibration and validation [83]. And fourth, the techniques employed for urban tree/forest recognition, classification, segmentation and change detection from remote sensing data are still in their infancy, even though the key advantage of remote sensing technology lies in its capability of integrating data from multiple sources with multi-spatial/spectral/temporal resolutions that can provide enhanced data on urban forest resources and more robust and interpretable information for assessing ecosystem services. 
In line with the aforementioned challenges, we present a set of future research directions on the application of remote sensing in an urban forest as follows:

(1) There is a need for robust algorithms to fully automate the co-registration of data captured by multiple sensors as well as an optimal combined strategy of fusion algorithms to integrate multi-source remote sensing data at the pixel, feature and landscape levels.

(2) Another direction is to calibrate modelling techniques (such as processing accuracy and efficiency in dealing with spatial/temporal co-registration and high data dimensionality) to long-term time series so that past and present monitoring and analyses can evolve to innovative forecasting with regard to the dynamics of urban forests and their ecosystem services. Ultimately, temporal analysis would become a precursor to predicting the future and informing long-term urban forest strategy based on trends derived from past observations [84].

(3) Owing to the complexity of natural and anthropogenic factors in urban areas, urban forest studies relying on remote sensing data at a larger scale are still at the experimental stage $[27,50]$. Multi-scale analyses would help to access spatial information over a wide range of scales from local to regional and even global. Yet, scale variations should be carefully considered when using remote sensing applications to inform land-use policies and the related estimation of ecosystem services provision.

\section{Concluding Remarks}

In tandem with the ever-growing availability of high-resolution remotely sensed imagery from diverse airborne and spaceborne platforms, research continues to broaden the application and utilisation of remote sensing techniques to support and advise urban forest studies, such as the accurate modelling and quantification of urban ecosystem services [27,35]. To effectively and adequately realise the potential of remote sensing, a strong connection and collaboration between urban foresters and remote sensing experts is highly advised. This conjoint synergy would allow to recognise and address the aforementioned challenges as well as ensure the optimisation of urban forests and their ecosystem services for long-term human wellbeing. 
Table 1. Classified studies in terms of applications and themes.

\begin{tabular}{|c|c|c|c|c|c|c|c|c|c|}
\hline \multirow[b]{3}{*}{ Applications } & \multicolumn{9}{|c|}{ Themes } \\
\hline & \multicolumn{5}{|c|}{ Multi-Source } & \multicolumn{2}{|c|}{ Multi-Temporal } & \multicolumn{2}{|c|}{ Multi-Scale } \\
\hline & $\begin{array}{l}\text { Single Remote } \\
\text { Sensing Data } \\
\text { Source }\end{array}$ & $\begin{array}{l}\text { Multiple Sources of } \\
\text { Satellite Imagery }\end{array}$ & $\begin{array}{l}\text { Satellite Imagery } \\
\text { and Airborne } \\
\text { LiDAR }\end{array}$ & $\begin{array}{l}\text { Satellite Imagery } \\
\text { and Aerial } \\
\text { Imagery }\end{array}$ & $\begin{array}{l}\text { Airborne LiDAR } \\
\text { and Aerial Imagery }\end{array}$ & Short Series & Long Series & $\begin{array}{l}\text { Local-/District- } \\
\text { City Level }\end{array}$ & $\begin{array}{l}\text { City-Regional } \\
\text { Level }\end{array}$ \\
\hline Tree biomass & & & {$[58,85]$} & & [47] & & & & \\
\hline Forest inventory & & & [86] & & [71] & & & & \\
\hline Canopy cover & [81] & {$[87]$} & {$[62,88]$} & [89] & {$[90,91]$} & {$[87,89,91]$} & {$[42,92]$} & [81] & \\
\hline Urban heat island & [93] & {$[51,53,57,74,78,94-97]$} & & {$[66,72,73]$} & [98] & {$[73,74,99]$} & {$[57,72,78]$} & {$[72,93]$} & \\
\hline Carbon storage & [82] & [79] & {$[58,59]$} & & {$[43,44,100]$} & & {$[79,92]$} & & [82] \\
\hline Water retention & [81] & & & & & & & [81] & \\
\hline Air quality & [101] & {$[102]$} & & & [103] & & & [101] & \\
\hline Forest fire & & {$[54,104]$} & [105] & & & & [104] & & \\
\hline Tree species & {$[48,101,106-108]$} & {$[102,109,110]$} & {$[64,111,112]$} & [113] & {$[43,69,103,114-116]$} & {$[108,109]$} & {$[48,106,107]$} & [101] & \\
\hline $\begin{array}{l}\text { Greenspace } \\
\text { configuration }\end{array}$ & [117] & {$[75-77,118-120]$} & [5] & & & {$[75,76]$} & {$[77,117-120]$} & {$[5,75]$} & [77] \\
\hline
\end{tabular}


Table 2. Strengths and limitations of multi-source, multi-temporal and multi-scale inputs.

\begin{tabular}{|c|c|c|}
\hline & Strengths & Limitations \\
\hline \multicolumn{3}{|l|}{ Multi-Source } \\
\hline Single remote sensing data source & - Involves low labour and high efficiency in data processing & $\begin{array}{l}\text { - Involves a trade-off between the highest quality spatial, } \\
\text { temporal and spectral resolution available }\end{array}$ \\
\hline Multiple sources of satellite imagery & $\begin{array}{l}\text { - Suitable for studying the urban heat island and greenspace (spatial) } \\
\text { configuration within cities } \\
\text { - A large amount of open-access images are available } \\
\text { - Dataset availability across a long time span (e.g., Landsat) allows } \\
\text { historical long-term studies } \\
\text { - Multiple sensors (e.g., high spatial and spectral resolution, thermal } \\
\text { band) allow a wide range of applications in urban forest studies }\end{array}$ & $\begin{array}{l}\text { - Image data processing is complex and requires data } \\
\text { fusion algorithms to extract similar features from multiple } \\
\text { images with different spectral bands } \\
\text { - Unsuited for studies on understory urban forests }\end{array}$ \\
\hline $\begin{array}{l}\text { Satellite imagery } \\
\text { and airborne LiDAR }\end{array}$ & $\begin{array}{l}\text { - Suitable for urban forest inventories, tree biomass and carbon storage } \\
\text { assessment, as well as tree species identification } \\
\text { - Point-cloud colourisation technique allows tree-level analysis by } \\
\text { having 3D point clouds with spectral detail }\end{array}$ & $\begin{array}{l}\text { - } \quad \text { Relatively high cost for LiDAR data acquisition } \\
\text { and processing } \\
\text { - Final accuracy is affected by the fetch interval between the } \\
\text { two data sources: satellite images and LiDAR }\end{array}$ \\
\hline $\begin{array}{l}\text { Satellite imagery } \\
\text { and aerial imagery }\end{array}$ & $\begin{array}{l}\text { - Aerial imagery with higher spatial resolution can improve the } \\
\text { classification of satellite images in urban forest applications }\end{array}$ & $\begin{array}{l}\text { - Airborne imagery acquisition requires more resources and } \\
\text { a careful plan and cannot be reiterated often due to costs } \\
\text { involved in the process }\end{array}$ \\
\hline $\begin{array}{l}\text { Airborne LiDAR } \\
\text { and aerial imagery }\end{array}$ & $\begin{array}{l}\text { - Suitable for urban forest inventories, tree biomass and carbon storage } \\
\text { calculations, and tree species identification that require high } \\
\text { estimation accuracy at small scale }\end{array}$ & $\begin{array}{l}\text { - Airborne LiDAR acquisition requires more resources and } \\
\text { a careful plan and cannot be reiterated often due to costs } \\
\text { involved in the process }\end{array}$ \\
\hline \multicolumn{3}{|l|}{ Multi-temporal } \\
\hline Short series & $\begin{array}{l}\text { - Suitable to estimate short-term changes in urban heat island effects, } \\
\text { canopy cover, tree species and greenspace spatial configuration, } \\
\text { especially before and after a certain event }\end{array}$ & $\begin{array}{l}\text { - Results need to be interpreted carefully, especially for the } \\
\text { short-term assessment of urban forest ecosystem services }\end{array}$ \\
\hline Long series & - Suitable for long-term phenological studies on urban forest areas & $\begin{array}{l}\text { Data quality of long-series imagery is particularly } \\
\text { dependent on weather conditions and availability of } \\
\text { cloud-free images }\end{array}$ \\
\hline \multicolumn{3}{|l|}{ Multi-Scale } \\
\hline Local-/district-city level & $\begin{array}{l}\text { - Suitable to determine the relationship between urban forest and } \\
\text { ecosystem services at the local scale and to scale up this relationship } \\
\text { at city level }\end{array}$ & $\begin{array}{l}\text { - Multi-scale studies are complex to carry out and require } \\
\text { through knowledge of different sensors and algorithms } \\
\text { for fusing multiple images }\end{array}$ \\
\hline City-regional level & $\begin{array}{l}\text { - Suitable for assessing the impact of green infrastructures on large } \\
\text { urban areas and to scale up the relative ecosystem services for the } \\
\text { whole city region }\end{array}$ & $\begin{array}{l}\text { - Mapping green infrastructures at multi-scale requires } \\
\text { thorough knowledge of different sensors and algorithms } \\
\text { for fusing multiple images }\end{array}$ \\
\hline
\end{tabular}


Table 3. Description of commonly used remote sensing products/platforms for urban forest studies.

\begin{tabular}{|c|c|c|c|c|c|c|c|}
\hline & Spatial Resolution & Number of Bands & Revisit Time & Thermal Data & Free of Charge & Temporal Coverage & Spatial Coverage \\
\hline ALOS & $\begin{array}{l}2.5 \mathrm{~m} \text { panchromatic } \\
10 \mathrm{~m} \text { multispectral }\end{array}$ & 5 & 46 days & No & No & 2006-2011 & Global \\
\hline ASTER & $\begin{array}{l}15 \mathrm{~m} \text { visible near infrared } \\
30 \mathrm{~m} \text { shortwave infrared } \\
90 \mathrm{~m} \text { thermal infrared }\end{array}$ & 14 & 16 days & No & Yes & 2000-present & Global \\
\hline IKONOS & $\begin{array}{l}0.82 \mathrm{~m} \text { panchromatic } \\
3.2 \mathrm{~m} \text { multispectral }\end{array}$ & 5 & 3 days & No & No & 1999-present & Global \\
\hline Landsat-5 (TM) & $\begin{array}{l}30 \mathrm{~m} \text { multispectral } \\
120 \mathrm{~m} \text { thermal }\end{array}$ & 7 & 16 days & Yes & Yes & 1984-2012 & Global \\
\hline Landsat-7 (ETM+) & $\begin{array}{l}15 \mathrm{~m} \text { panchromatic } \\
30 \mathrm{~m} \text { multispectra } \\
160 \mathrm{~m} \text { thermal }\end{array}$ & 8 & 16 days & Yes & Yes & 1999-present & Global \\
\hline Landsat-8 (OLI/TIRS) & $\begin{array}{l}15 \mathrm{~m} \text { panchromatic } \\
30 \mathrm{~m} \text { multispectral } \\
100 \mathrm{~m} \text { thermal }\end{array}$ & 11 & 16 days & Yes & Yes & 2013-present & Global \\
\hline MODIS & $\begin{array}{l}\text { 250/500/1000 m multispectral } \\
500 / 1000 \mathrm{~m} \text { thermal }\end{array}$ & 36 & 1/4/8/16 days & Yes & Yes & 2000-present & Global \\
\hline NAIP aerial imagery & $1 \mathrm{~m}$ multispectral & $3 / 4$ & Sub-annual & No & Yes & $2003-2015$ & CONUS \\
\hline RapidEye & $6.5 \mathrm{~m}$ multispectral & 5 & 1 day & No & No & 2008-present & Global \\
\hline Sentinel-2A (MSI) & 10/20/60 m multispectral & 13 & 10 days & No & Yes & 2015-present & Global \\
\hline SPOT-5 & $\begin{array}{l}\text { 5/10 m panchromatic } \\
10 / 20 \mathrm{~m} \text { multispectral }\end{array}$ & 6 & 3 days & No & Yes & 2002-present & Global \\
\hline WorldView-2 & $\begin{array}{l}0.5 \mathrm{~m} \text { panchromatic } \\
1.84 \mathrm{~m} \text { multispectral }\end{array}$ & 9 & 1 day & No & No & 2009-present & Global \\
\hline WorldView-3 & $\begin{array}{l}0.31 \mathrm{~m} \text { panchromatic } \\
1.24 \mathrm{~m} \text { multispectral }\end{array}$ & 9 & 1 day & No & No & 2014-present & Global \\
\hline
\end{tabular}




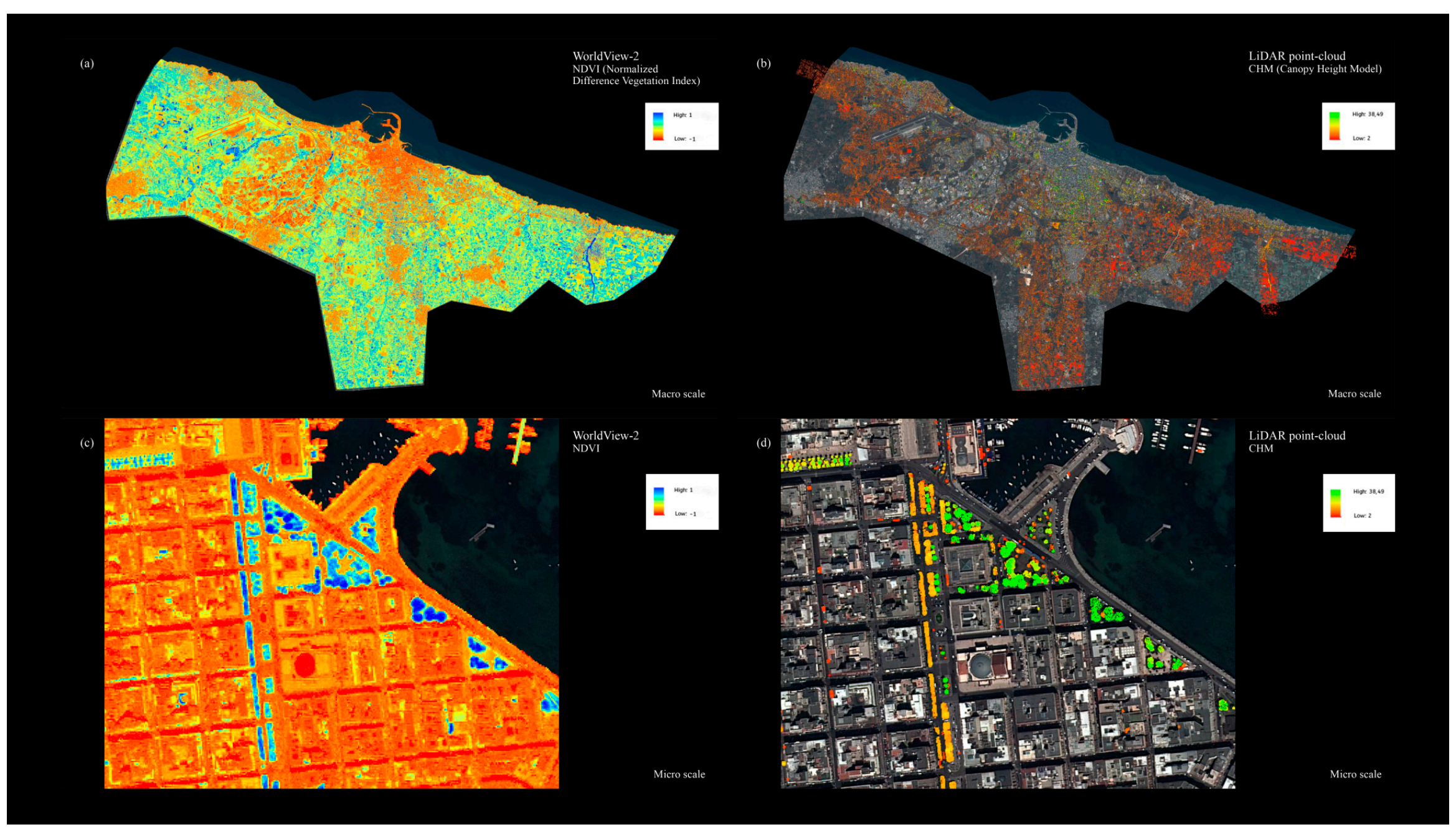

Figure 1. Examples of satellite imagery and LiDAR point-cloud data: (a) WorldView-2 NDVI at city-regional level, (b) LiDAR point-cloud Canopy Height Model (CHM) at city- regional level, (c) WorldView-2 NDVI at local-/district-city level, (d) LiDAR point-cloud CHM local-/district-city level. 
Supplementary Materials: The following are available online at http://www.mdpi.com/2072-4292/11/10/1144/s1.

Author Contributions: Conceptualisation, R.L., X.L. and W.Y.C.; sources of review studies, X.L.; writing一original draft preparation, X.L.; writing—review and editing, W.Y.C., R.L. and G.S.; visualisation, X.L.; supervision, R.L.

Funding: This research was funded by The University of Hong Kong, Seed Fund for Basic Research, 2018-2020.

Acknowledgments: The authors also wish to acknowledge Yole DeBellis for contributing to the review of this work and for editing the language of the manuscript.

Conflicts of Interest: The authors declare no conflict of interest.

\section{References}

1. Nesbitt, L.; Hotte, N.; Barron, S.; Cowan, J.; Sheppard, S.R.J. The social and economic value of cultural ecosystem services provided by urban forests in North America: A review and suggestions for future research. Urban For. Urban Green. 2017, 25, 103-111. [CrossRef]

2. Davies, H.J.; Doick, K.J.; Hudson, M.D.; Schaafsma, M.; Schreckenberg, K.; Valatin, G. Business attitudes towards funding ecosystem services provided by urban forests. Ecosyst. Serv. 2018, 32, 159-169. [CrossRef]

3. Fahey, R.T.; Casali, M. Distribution of forest ecosystems over two centuries in a highly urbanized landscape. Landsc. Urban Plan. 2017, 164, 13-24. [CrossRef]

4. Roman, L.A.; Pearsall, H.; Eisenman, T.S.; Conway, T.M.; Fahey, R.T.; Landry, S.; Vogt, J.; van Doorn, N.S.; Grove, J.M.; Locke, D.H.; et al. Human and biophysical legacies shape contemporary urban forests: A literature synthesis. Urban For. Urban Green. 2018, 31, 157-168. [CrossRef]

5. Lafortezza, R.; Giannico, V. Combining high-resolution images and LiDAR data to model ecosystem services perception in compact urban systems. Ecol. Indic. 2019, 96, 87-98. [CrossRef]

6. Kowarik, I. Novel urban ecosystems, biodiversity, and conservation. Environ. Pollut. 2011, 159, $1974-1983$. [CrossRef]

7. Chen, W.Y. Urban Nature and Urban Ecosystem Services. In Greening Cities; Springer: Berlin/Heidelberg, Germany, 2017; pp. 181-199.

8. Nowak, D.J.; Noble, M.H.; Sisinni, S.M.; Dwyer, J.F. People \& trees-Assessing the US urban forest resource. J. For. 2001, 99, 37-42.

9. Konijnendijk, C.C.; Ricard, R.M.; Kenney, A.; Randrup, T.B. Defining urban forestry-A comparative perspective of North America and Europe. Urban For. Urban Green. 2006, 4, 93-103. [CrossRef]

10. Kenney, W.A.; Van Wassenaer, P.J.; Satel, A.L. Criteria and indicators for strategic urban forest planning and management. Arboric. Urban. For. 2011, 37, 108-117.

11. Steenberg, J.W.; Duinker, P.N.; Nitoslawski, S.A. Ecosystem-based management revisited: Updating the concepts for urban forests. Landsc. Urban Plan. 2019, 186, 24-35. [CrossRef]

12. Elmqvist, T.; Setala, H.; Handel, S.N.; van der Ploeg, S.; Aronson, J.; Blignaut, J.N.; Gomez-Baggethun, E.; Nowak, D.J.; Kronenberg, J.; de Groot, R. Benefits of restoring ecosystem services in urban areas. Curr. Opin. Environ. Sustain. 2015, 14, 101-108. [CrossRef]

13. Long, L.C.; D'Amico, V.; Frank, S.D. Urban forest fragments buffer trees from warming and pests. Sci. Total Environ. 2019, 658, 1523-1530. [CrossRef]

14. Costanza, R.; d'Arge, R.; De Groot, R.; Farber, S.; Grasso, M.; Hannon, B.; Limburg, K.; Naeem, S.; O’Neill, R.V.; Paruelo, J.; et al. The value of the world's ecosystem services and natural capital. Nature 1997, 387, 253-260. [CrossRef]

15. De Groot, R.S.; Alkemade, R.; Braat, L.; Hein, L.; Willemen, L. Challenges in integrating the concept of ecosystem services and values in landscape planning, management and decision making. Ecol. Complex. 2010, 7, 260-272. [CrossRef]

16. Endreny, T.; Santagata, R.; Perna, A.; De Stefano, C.; Rallo, R.F.; Ulgiati, S. Implementing and managing urban forests: A much needed conservation strategy to increase ecosystem services and urban wellbeing. Ecol. Model. 2017, 360, 328-335. [CrossRef]

17. Canetti, A.; Garrastazu, M.C.; de Mattos, P.P.; Braz, E.M.; Netto, S.P. Understanding multi-temporal urban forest cover using high resolution images. Urban For. Urban Green. 2018, 29, 106-112. [CrossRef]

18. Song, X.P.; Tan, P.Y.; Edwards, P.; Richards, D. The economic benefits and costs of trees in urban forest stewardship: A systematic review. Urban For. Urban Green. 2018, 29, 162-170. [CrossRef] 
19. Doick, K.J.; Hutchings, T. Air Temperature Regulation by Urban Trees and Green Infrastructure; Forestry Commission: Edinburgh, UK, 2013.

20. Wang, Z.H.; Zhao, X.X.; Yang, J.C.; Song, J.Y. Cooling and energy saving potentials of shade trees and urban lawns in a desert city. Appl. Energy 2016, 161, 437-444. [CrossRef]

21. Armson, D.; Stringer, P.; Ennos, A.R. The effect of street trees and amenity grass on urban surface water runoff in Manchester, UK. Urban For. Urban Green. 2013, 12, 282-286. [CrossRef]

22. Coutts, A.M.; Tapper, N.J.; Beringer, J.; Loughnan, M.; Demuzere, M. Watering our cities: The capacity for Water Sensitive Urban Design to support urban cooling and improve human thermal comfort in the Australian context. Prog. Phys. Geogr. 2013, 37, 2-28. [CrossRef]

23. Baro, F.; Chaparro, L.; Gomez-Baggethun, E.; Langemeyer, J.; Nowak, D.J.; Terradas, J. Contribution of Ecosystem Services to Air Quality and Climate Change Mitigation Policies: The Case of Urban Forests in Barcelona, Spain. Ambio 2014, 43, 466-479. [CrossRef]

24. Nowak, D.J.; Greenfield, E.J.; Hoehn, R.E.; Lapoint, E. Carbon storage and sequestration by trees in urban and community areas of the United States. Environ. Pollut. 2013, 178, 229-236. [CrossRef]

25. Chen, W.Y. The role of urban green infrastructure in offsetting carbon emissions in 35 major Chinese cities: A nationwide estimate. Cities 2015, 44, 112-120. [CrossRef]

26. Giannico, V.; Lafortezza, R.; John, R.; Sanesi, G.; Pesola, L.; Chen, J.Q. Estimating Stand Volume and Above-Ground Biomass of Urban Forests Using LiDAR. Remote Sens. 2016, 8, 339. [CrossRef]

27. Tigges, J.; Lakes, T. High resolution remote sensing for reducing uncertainties in urban forest carbon offset life cycle assessments. Carbon Balance Manag. 2017, 12. [CrossRef]

28. Hurley, P.T.; Emery, M.R. Locating provisioning ecosystem services in urban forests: Forageable woody species in New York City, USA. Landsc. Urban Plan. 2018, 170, 266-275. [CrossRef]

29. Aleixo, K.P.; de Faria, L.B.; Groppo, M.; Castro, M.M.D.; da Silva, C.I. Spatiotemporal distribution of floral resources in a Brazilian city: Implications for the maintenance of pollinators, especially bees. Urban For. Urban Green. 2014, 13, 689-696. [CrossRef]

30. Lowenstein, D.M.; Matteson, K.C.; Minor, E.S. Diversity of wild bees supports pollination services in an urbanized landscape. Oecologia 2015, 179, 811-821. [CrossRef]

31. Potter, A.; LeBuhn, G. Pollination service to urban agriculture in San Francisco, CA. Urban Ecosyst. 2015, 18, 885-893. [CrossRef]

32. Meyer, M.A.; Rathmann, J.; Schulz, C. Spatially-explicit mapping of forest benefits and analysis of motivations for everyday-life's visitors on forest pathways in urban and rural contexts. Landsc. Urban Plan. 2019, 185, 83-95. [CrossRef]

33. Eriksson, L.; Nordlund, A.; Olsson, O.; Westin, K. Beliefs about urban fringe forests among urban residents in Sweden. Urban For. Urban Green. 2012, 11, 321-328. [CrossRef]

34. Haase, D.; Frantzeskaki, N.; Elmqvist, T. Ecosystem Services in Urban Landscapes: Practical Applications and Governance Implications. Ambio 2014, 43, 407-412. [CrossRef]

35. Singh, K.K.; Gagne, S.A.; Meentemeyer, R.K. Urban forests and human well-being. In Comprehensive Remote Sensing; Liang, S.L., Ed.; Elsevier: Oxford, UK, 2018; Volume 9, pp. 287-305.

36. Sass, C.K.; Lodder, R.A.; Lee, B.D. Combining biophysical and socioeconomic suitability models for urban forest planning. Urban For. Urban Green. 2019, 38, 371-382. [CrossRef]

37. Hotta, K.; Ishii, H.; Sasaki, T.; Doi, N.; Azuma, W.; Oyake, Y.; Imanishi, J.; Yoshida, H. Twenty-one years of stand dynamics in a 33-year-old urban forest restoration site at Kobe Municipal Sports Park, Japan. Urban For. Urban Green. 2015, 14, 309-314. [CrossRef]

38. Dobbs, C.; Escobedo, F.J.; Zipperer, W.C. A framework for developing urban forest ecosystem services and goods indicators. Landsc. Urban Plan. 2011, 99, 196-206. [CrossRef]

39. Bartesaghi-Koc, C.; Osmond, P.; Peters, A. Mapping and classifying green infrastructure typologies for climate-related studies based on remote sensing data. Urban For. Urban Green. 2019, 37, 154-167. [CrossRef]

40. Myeong, S.; Nowak, D.J.; Duggin, M.J. A temporal analysis of urban forest carbon storage using remote sensing. Remote Sens. Environ. 2006, 101, 277-282. [CrossRef]

41. $\mathrm{Pu}$, R.L. Mapping urban forest tree species using IKONOS imagery: Preliminary results. Environ. Monit. Assess. 2011, 172, 199-214. [CrossRef] 
42. Song, Y.; Imanishi, J.; Sasaki, T.; Ioki, K.; Morimoto, Y. Estimation of broad-leaved canopy growth in the urban forested area using multi-temporal airborne LiDAR datasets. Urban For. Urban Green. 2016, 16, 142-149. [CrossRef]

43. Alonzo, M.; McFadden, J.P.; Nowak, D.J.; Roberts, D.A. Mapping urban forest structure and function using hyperspectral imagery and lidar data. Urban For. Urban Green. 2016, 17, 135-147. [CrossRef]

44. Chen, G.; Ozelkan, E.; Singh, K.K.; Zhou, J.; Brown, M.R.; Meentemeyer, R.K. Uncertainties in mapping forest carbon in urban ecosystems. J. Environ. Manag. 2017, 187, 229-238. [CrossRef]

45. Fassnacht, F.E.; Latifi, H.; Sterenczak, K.; Modzelewska, A.; Lefsky, M.; Waser, L.T.; Straub, C.; Ghosh, A. Review of studies on tree species classification from remotely sensed data. Remote Sens. Environ. 2016, 186, 64-87. [CrossRef]

46. Singh, K.K.; Chen, G.; McCarter, J.B.; Meentemeyer, R.K. Effects of LiDAR point density and landscape context on estimates of urban forest biomass. ISPRS J. Photogramm. 2015, 101, 310-322. [CrossRef]

47. Lee, J.H.; Ko, Y.K.; McPherson, E.G. The feasibility of remotely sensed data to estimate urban tree dimensions and biomass. Urban For. Urban Green. 2016, 16, 208-220. [CrossRef]

48. Pu, R.L.; Landry, S.; Yu, Q.Y. Assessing the potential of multi-seasonal high resolution Pleiades satellite imagery for mapping urban tree species. Int. J. Appl. Earth Obs. 2018, 71, 144-158. [CrossRef]

49. Herold, M.; Roberts, D.A.; Gardner, M.E.; Dennison, P.E. Spectrometry for urban area remote sensing-Development and analysis of a spectral library from 350 to $2400 \mathrm{~nm}$. Remote Sens. Environ. 2004, 91, 304-319. [CrossRef]

50. Wilkes, P.; Disney, M.; Vicari, M.B.; Calders, K.; Burt, A. Estimating urban above ground biomass with multi-scale LiDAR. Carbon Balance Manag. 2018, 13. [CrossRef]

51. Ren, Z.B.; He, X.Y.; Zheng, H.F.; Zhang, D.; Yu, X.Y.; Shen, G.Q.; Guo, R.C. Estimation of the Relationship between Urban Park Characteristics and Park Cool Island Intensity by Remote Sensing Data and Field Measurement. Forests 2013, 4, 868-886. [CrossRef]

52. Qin, Z.; Karnieli, A.; Berliner, P. A mono-window algorithm for retrieving land surface temperature from Landsat TM data and its application to the Israel-Egypt border region. Int. J. Remote Sens. 2001, 22, 3719-3746. [CrossRef]

53. Kong, F.H.; Yin, H.W.; James, P.; Hutyra, L.R.; He, H.S. Effects of spatial pattern of greenspace on urban cooling in a large metropolitan area of eastern China. Landsc. Urban Plan. 2014, 128, 35-47. [CrossRef]

54. Modugno, S.; Balzter, H.; Cole, B.; Borrelli, P. Mapping regional patterns of large forest fires in Wildland-Urban Interface areas in Europe. J. Environ. Manag. 2016, 172, 112-126. [CrossRef]

55. Stuczynski, T.; Siebielec, G.; Korzeniowska-Puculek, R.; Koza, P.; Pudelko, R.; Lopatka, A.; Kowalik, M. Geographical location and key sensitivity issues of post-industrial regions in Europe. Environ. Monit. Assess. 2009, 151, 77-91. [CrossRef]

56. Suau-Sanchez, P.; Burghouwt, G.; Pallares-Barbera, M. An appraisal of the CORINE land cover database in airport catchment area analysis using a GIS approach. J. Air Transp. Manag. 2014, 34, 12-16. [CrossRef]

57. Di Leo, N.; Escobedo, F.J.; Dubbeling, M. The role of urban green infrastructure in mitigating land surface temperature in Bobo-Dioulasso, Burkina Faso. Environ. Dev. Sustain. 2016, 18, 373-392. [CrossRef]

58. Raciti, S.M.; Hutyra, L.R.; Newell, J.D. Mapping carbon storage in urban trees with multi-source remote sensing data: Relationships between biomass, land use, and demographics in Boston neighborhoods. Sci. Total Environ. 2014, 500, 72-83. [CrossRef]

59. Schreyer, J.; Tigges, J.; Lakes, T.; Churkina, G. Using Airborne LiDAR and QuickBird Data for Modelling Urban Tree Carbon Storage and Its Distribution-A Case Study of Berlin. Remote Sens. 2014, 6, 10636-10655. [CrossRef]

60. Hyyppa, J.; Hyyppa, H.; Leckie, D.; Gougeon, F.; Yu, X.; Maltamo, M. Review of methods of small-footprint airborne laser scanning for extracting forest inventory data in boreal forests. Int. J. Remote Sens. 2008, 29, 1339-1366. [CrossRef]

61. Popescu, S.C.; Wynne, R.H. Seeing the trees in the forest: Using lidar and multispectral data fusion with local filtering and variable window size for estimating tree height. Photogramm. Eng. Remote Sens. 2004, 70, 589-604. [CrossRef]

62. Parmehr, E.G.; Amati, M.; Fraser, C.S. Mapping Urban Tree Canopy Cover Using Fused Airborne Lidar and Satellite Imagery Data. SPRS Ann. Photogramm. Remote Sens. Spat. Inf. Sci. 2016, 3, 181-186. [CrossRef] 
63. Parmehr, E.G.; Fraser, C.S.; Zhang, C.S.; Leach, J. Automatic Co-Registration of Satellite Imagery and Lidar Data Using Local Mutual Information. Int. Geosci. Remote Sens. 2013, 1099-1102. [CrossRef]

64. Singh, K.K.; Davis, A.J.; Meentemeyer, R.K. Detecting understory plant invasion in urban forests using LiDAR. Int. J. Appl. Earth Obs. 2015, 38, 267-279. [CrossRef]

65. Hsieh, P.F.; Lee, L.C.; Chen, N.Y. Effect of spatial resolution on classification errors of pure and mixed pixels in remote sensing. IEEE Trans. Geosci. Remote Sens. 2001, 39, 2657-2663. [CrossRef]

66. Sung, C.Y. Mitigating surface urban heat island by a tree protection policy: A case study of The Woodland, Texas, USA. Urban For. Urban Green. 2013, 12, 474-480. [CrossRef]

67. Benz, U.C.; Hofmann, P.; Willhauck, G.; Lingenfelder, I.; Heynen, M. Multi-resolution, object-oriented fuzzy analysis of remote sensing data for GIS-ready information. ISPRS J. Photogramm. 2004, 58, 239-258. [CrossRef]

68. Agarwal, S.; Vailshery, L.S.; Jaganmohan, M.; Nagendra, H. Mapping Urban Tree Species Using Very High Resolution Satellite Imagery: Comparing Pixel-Based and Object-Based Approaches. ISPRS Int J. Geo-Inf. 2013, 2, 220-236. [CrossRef]

69. Alonzo, M.; Bookhagen, B.; Roberts, D.A. Urban tree species mapping using hyperspectral and lidar data fusion. Remote Sens. Environ. 2014, 148, 70-83. [CrossRef]

70. Alonzo, M.; Roth, K.; Roberts, D. Identifying Santa Barbara's urban tree species from AVIRIS imagery using canonical discriminant analysis. Remote Sens. Lett. 2013, 4, 513-521. [CrossRef]

71. Zhang, C.Y.; Zhou, Y.H.; Qiu, F. Individual Tree Segmentation from LiDAR Point Clouds for Urban Forest Inventory. Remote Sens. 2015, 7, 7892-7913. [CrossRef]

72. Duncan, J.M.A.; Boruff, B.; Saunders, A.; Sun, Q.; Hurley, J.; Amati, M. Turning down the heat: An enhanced understanding of the relationship between urban vegetation and surface temperature at the city scale. Sci. Total Environ. 2019, 656, 118-128. [CrossRef]

73. Rogan, J.; Ziemer, M.; Martin, D.; Ratick, S.; Cuba, N.; DeLauer, V. The impact of tree cover loss on land surface temperature: A case study of central Massachusetts using Landsat Thematic Mapper thermal data. Appl. Geogr. 2013, 45, 49-57. [CrossRef]

74. Zuo, S.D.; Dai, S.Q.; Song, X.D.; Xu, C.D.; Liao, Y.L.; Chang, W.Y.; Chen, Q.; Li, Y.Y.; Tang, J.F.; Man, W.; et al. Determining the Mechanisms that Influence the Surface Temperature of Urban Forest Canopies by Combining Remote Sensing Methods, Ground Observations, and Spatial Statistical Models. Remote Sens. 2018, 10, 1814. [CrossRef]

75. Qian, Y.G.; Zhou, W.Q.; Li, W.F.; Han, L.J. Understanding the dynamic of greenspace in the urbanized area of Beijing based on high resolution satellite images. Urban For. Urban Green. 2015, 14, 39-47. [CrossRef]

76. Qian, Y.G.; Zhou, W.Q.; Yu, W.J.; Pickett, S.T.A. Quantifying spatiotemporal pattern of urban greenspace: New insights from high resolution data. Landsc. Ecol. 2015, 30, 1165-1173. [CrossRef]

77. Yang, J.; Huang, C.H.; Zhang, Z.Y.; Wang, L. The temporal trend of urban green coverage in major Chinese cities between 1990 and 2010. Urban For. Urban Green. 2014, 13, 19-27. [CrossRef]

78. Adams, M.P.; Smith, P.L. A systematic approach to model the influence of the type and density of vegetation cover on urban heat using remote sensing. Landsc. Urban Plan. 2014, 132, 47-54. [CrossRef]

79. Bae, J.; Ryu, Y. Land use and land cover changes explain spatial and temporal variations of the soil organic carbon stocks in a constructed urban park. Landsc. Urban Plan. 2015, 136, 57-67. [CrossRef]

80. Guo, G.; Wu, Z.; Xiao, R.; Chen, Y.; Liu, X.; Zhang, X. Impacts of urban biophysical composition on land surface temperature in urban heat island clusters. Landsc. Urban Plan. 2015, 135, 1-10. [CrossRef]

81. Yao, L.; Chen, L.D.; Wei, W.; Sun, R.H. Potential reduction in urban runoff by green spaces in Beijing: A scenario analysis. Urban For. Urban Green. 2015, 14, 300-308. [CrossRef]

82. McPherson, E.G.; Xiao, Q.F.; Aguaron, E. A new approach to quantify and map carbon stored, sequestered and emissions avoided by urban forests. Landsc. Urban Plan. 2013, 120, 70-84. [CrossRef]

83. Pettorelli, N.; Buhne, H.S.T.; Tulloch, A.; Dubois, G.; Macinnis-Ng, C.; Queiros, A.M.; Keith, D.A.; Wegmann, M.; Schrodt, F.; Stellmes, M.; et al. Satellite remote sensing of ecosystem functions: Opportunities, challenges and way forward. Remote Sens. Ecol. Conserv. 2018, 4, 71-93. [CrossRef]

84. Kuenzer, C.; Dech, S.; Wagner, W. Remote sensing time series revealing land surface dynamics: Status quo and the pathway ahead. In Remote Sensing Time Series; Springer: Berlin/Heidelberg, Germany, 2015; pp. 1-24.

85. He, C.; Convertino, M.; Feng, Z.K.; Zhang, S.Y. Using LiDAR Data to Measure the 3D Green Biomass of Beijing Urban Forest in China. PLoS ONE 2013, 8. [CrossRef] 
86. Huang, Y.; Yu, B.L.; Zhou, J.H.; Hu, C.L.; Tan, W.Q.; Hu, Z.M.; Wu, J.P. Toward automatic estimation of urban green volume using airborne LiDAR data and high resolution Remote Sensing images. Front. Earth Sci. 2013, 7, 43-54. [CrossRef]

87. Chen, L.X.; Wang, L.Q.; Li, G.; Ma, F.W.; Zhang, Z.Q. Understanding treescape changes as the basis of urban forest planning in fringe areas. Ecol. Indic. 2018, 95, 117-126. [CrossRef]

88. Parmehr, E.G.; Amati, M.; Taylor, E.J.; Livesley, S.J. Estimation of urban tree canopy cover using random point sampling and remote sensing methods. Urban For. Urban Green. 2016, 20, 160-171. [CrossRef]

89. Hostetler, A.E.; Rogan, J.; Martin, D.; DeLauer, V.; O'Neil-Dunne, J. Characterizing tree canopy loss using multi-source GIS data in Central Massachusetts, USA. Remote Sens. Lett. 2013, 4, 1137-1146. [CrossRef]

90. O'Neil-Dunne, J.; MacFaden, S.; Royar, A. A Versatile, Production-Oriented Approach to High-Resolution Tree-Canopy Mapping in Urban and Suburban Landscapes Using GEOBIA and Data Fusion. Remote Sens. 2014, 6, 12837-12865. [CrossRef]

91. Ossola, A.; Hopton, M.E. Measuring urban tree loss dynamics across residential landscapes. Sci. Total Environ. 2018, 612, 940-949. [CrossRef]

92. McGovern, M.; Pasher, J. Canadian urban tree canopy cover and carbon sequestration status and change 1990-2012. Urban For. Urban Green. 2016, 20, 227-232. [CrossRef]

93. Feyisa, G.L.; Dons, K.; Meilby, H. Efficiency of parks in mitigating urban heat island effect: An example from Addis Ababa. Landsc. Urban Plan. 2014, 123, 87-95. [CrossRef]

94. Fan, C.; Myint, S.W.; Zheng, B.J. Measuring the spatial arrangement of urban vegetation and its impacts on seasonal surface temperatures. Prog. Phys. Geogr. 2015, 39, 199-219. [CrossRef]

95. Ren, Z.B.; Zheng, H.F.; He, X.Y.; Zhang, D.; Yu, X.Y. Estimation of the Relationship Between Urban Vegetation Configuration and Land Surface Temperature with Remote Sensing. J. Indian Soc. Remote Sens. 2015, 43, 89-100. [CrossRef]

96. Wu, D.; Wang, Y.F.; Fan, C.; Xia, B.C. Thermal environment effects and interactions of reservoirs and forests as urban blue-green infrastructures. Ecol. Indic. 2018, 91, 657-663. [CrossRef]

97. Huang, C.D.; Ye, X.Y. Spatial Modeling of Urban Vegetation and Land Surface Temperature: A Case Study of Beijing. Sustainability 2015, 7, 9478-9504. [CrossRef]

98. Davis, A.Y.; Jung, J.H.; Pijanowski, B.C.; Minor, E.S. Combined vegetation volume and "greenness" affect urban air temperature. Appl. Geogr. 2016, 71, 106-114. [CrossRef]

99. Ren, Y.; Deng, L.Y.; Zuo, S.D.; Song, X.D.; Liao, Y.L.; Xu, C.D.; Chen, Q.; Hua, L.Z.; Li, Z.W. Quantifying the influences of various ecological factors on land surface temperature of urban forests. Environ. Pollut. 2016, 216, 519-529. [CrossRef]

100. Godwin, C.; Chen, G.; Singh, K.K. The impact of urban residential development patterns on forest carbon density: An integration of LiDAR, aerial photography and field mensuration. Landsc. Urban Plan. 2015, 136, 97-109. [CrossRef]

101. Chaturvedi, A.; Kamble, R.; Patil, N.G.; Chaturvedi, A. City-forest relationship in Nagpur: One of the greenest cities of India. Urban For. Urban Green. 2013, 12, 79-87. [CrossRef]

102. Marando, F.; Salvatori, E.; Fusaro, L.; Manes, F. Removal of PM10 by Forests as a Nature-Based Solution for Air Quality Improvement in the Metropolitan City of Rome. Forests 2016, 7, 150. [CrossRef]

103. Bottalico, F.; Travaglini, D.; Chirici, G.; Garfi, V.; Giannetti, F.; De Marco, A.; Fares, S.; Marchetti, M.; Nocentini, S.; Paoletti, E.; et al. A spatially-explicit method to assess the dry deposition of air pollution by urban forests in the city of Florence, Italy. Urban For. Urban Green. 2017, 27, 221-234. [CrossRef]

104. Michael, Y.; Lensky, I.M.; Brenner, S.; Tchetchik, A.; Tessler, N.; Helman, D. Economic Assessment of Fire Damage to Urban Forest in the Wildland-Urban Interface Using Planet Satellites Constellation Images. Remote Sens. 2018, 10, 1479. [CrossRef]

105. Whitman, E.; Rapaport, E.; Sherren, K. Modeling Fire Susceptibility to Delineate Wildland-Urban Interface for Municipal-Scale Fire Risk Management. Environ. Manag. 2013, 52, 1427-1439. [CrossRef]

106. Tigges, J.; Lakes, T.; Hostert, P. Urban vegetation classification: Benefits of multitemporal RapidEye satellite data. Remote Sens. Environ. 2013, 136, 66-75. [CrossRef]

107. Singh, K.K.; Chen, Y.H.; Smart, L.; Gray, J.; Meentemeyer, R.K. Infra-annual phenology for detecting understory plant invasion in urban forests. ISPRS J. Photogramm. 2018, 142, 151-161. [CrossRef] 
108. Le Louarn, M.; Clergeau, P.; Briche, E.; Deschamps-Cottin, M. “Kill Two Birds with One Stone": Urban Tree Species Classification Using Bi-Temporal Pleiades Images to Study Nesting Preferences of an Invasive Bird. Remote Sens. 2017, 9, 916. [CrossRef]

109. Li, D.; Ke, Y.H.; Gong, H.L.; Li, X.J. Object-Based Urban Tree Species Classification Using Bi-Temporal WorldView-2 and WorldView-3 Images. Remote Sens. 2015, 7, 16917-16937. [CrossRef]

110. Ozkan, U.Y.; Ozdemir, I.; Saglam, S.; Yesil, A.; Demirel, T. Evaluating the Woody Species Diversity by Means of Remotely Sensed Spectral and Texture Measures in the Urban Forests. J. Indian Soc. Remote Sens. 2016, 44, 687-697. [CrossRef]

111. Gillespie, T.; de Goede, J.; Aguilar, L.; Jenerette, G.; Fricker, G.; Avolio, M.; Pincetl, S.; Johnston, T.; Clarke, L.; Pataki, D. Predicting tree species richness in urban forests. Urban Ecosyst. 2017, 20, 839-849. [CrossRef]

112. Plant, L.; Sipe, N. Adapting and applying evidence gathering techniques for planning and investment in street trees: A case study from Brisbane, Australia. Urban For. Urban Green. 2016, 19, 79-87. [CrossRef]

113. Shouse, M.; Liang, L.; Fei, S.L. Identification of understory invasive exotic plants with remote sensing in urban forests. Int. J. Appl. Earth Obs. 2013, 21, 525-534. [CrossRef]

114. Gu, H.; Singh, A.; Townsend, P.A. Detection of gradients of forest composition in an urban area using imaging spectroscopy. Remote Sens. Environ. 2015, 167, 168-180. [CrossRef]

115. Liu, L.X.; Coops, N.C.; Aven, N.W.; Pang, Y. Mapping urban tree species using integrated airborne hyperspectral and LiDAR remote sensing data. Remote Sens. Environ. 2017, 200, 170-182. [CrossRef]

116. Pontius, J.; Hanavan, R.P.; Hallett, R.A.; Cook, B.D.; Corp, L.A. High spatial resolution spectral unmixing for mapping ash species across a complex urban environment. Remote Sens. Environ. 2017, 199, 360-369. [CrossRef]

117. Ren, Z.B.; Wei, H.X. Spatiotemporal Patterns of Urban Forest Basal Area under China's Rapid Urban Expansion and Greening: Implications for Urban Green Infrastructure Management. (Retraction of Vol 9, $\operatorname{Pg}$ 272, 2018). Forests 2018, 9, 721. [CrossRef]

118. Li, Y.; Xue, C.Y.; Shao, H.; Shi, G.; Jiang, N. Study of the Spatiotemporal Variation Characteristics of Forest Landscape Patterns in Shanghai from 2004 to 2014 Based on Multisource Remote Sensing Data. Sustainability 2018, 10, 4397. [CrossRef]

119. Cui, N.; Feng, C.C.; Wang, D.; Li, J.; Guo, L. The Effects of Rapid Urbanization on Forest Landscape Connectivity in Zhuhai City, China. Sustainability 2018, 10, 3381. [CrossRef]

120. Kanniah, K.D. Quantifying green cover change for sustainable urban planning: A case of Kuala Lumpur, Malaysia. Urban For. Urban Green. 2017, 27, 287-304. [CrossRef] 